\title{
$O$ fenômeno da modernidade na Porto Alegre do século XIX
}

\author{
Isadora Eckardt da Silva
}

\begin{abstract}
Resumo: A obra Os viajantes olham Porto Alegre seleciona as partes dos relatos de viagem centralizados em Porto Alegre, os quais apresentam a cidade que começava a dar seus primeiros ares de metrópole. Observa-se elementos tipicamente citadinos, tais como o traçado das ruas, o aumento da população, o crescimento do número de prédios e moradias; e aspectos de modernização propriamente ditos como, por exemplo, a introdução de linhas de bonde, a pavimentação das ruas, o surgimento de casas e prédios mais elegantes. O século XIX é a época ideal para se observar o fenômeno urbano, pois foi neste período que a modernização se impôs. Há neste momento o surgimento de grandes metrópoles e de cidades brasileiras que estavam apenas se formando, como foi o caso de Porto Alegre.
\end{abstract}

Palavras-chave: viagem; modernidade; cidade

\begin{abstract}
The book Os viajantes olham Porto Alegre features selected excerpts of travel reports in which the travelers talk about Porto Alegre. On this article, I intend to analyze some of these passages, the ones that present a town that was just showing its first modern aspects. We can notice some elements that typically appear in a urban area, such as streets, the increase of population, the increase in the number of buildings and homes; and modern aspects as well, such as streetcars, street pavement, and more elegant houses and buildings. The nineteenth century is the best period of time for us to observe the urban phenomenon, since it was by this time that the modernization process imposed itself. Big cities appeared, as well as Brazilian cities, which were just at their beginning, as Porto Alegre, for example.
\end{abstract}

Keywords: travel; modernity; city

Durante o século XIX, inúmeros viajantes, em sua maioria europeus, percorreram as cidades brasileiras, olhando-as sob a influência do fenômeno da Modernidade, do qual nossas cidades ainda estavam longe, o que causava estranhamento e uma impressão de barbárie nestes viajantes. José Carlos Barreiro comenta esta peculiaridade do olhar dos viajantes europeus deste período:

Concepções como as do paraíso terreal [...] vigentes no período anterior, dão lugar a uma espécie de racionalidade que leva às últimas conseqüências a dominação cega do homem sobre a natureza e sobre os outros homens. A referência cultural dos viajantes estrangeiros passa a ser a de um tempo que se convencionou chamar de modernidade [...] (BARREIRO, 2002, p.10)

Este olhar forasteiro, o qual capta a alteridade, é extremamente importante por analisar outros aspectos que não são percebidos pelos autóctones. Walter Benjamin comenta sobre a importância desta visão de quem vem de fora:

Se dividirmos os retratos existentes de cidades em dois grupos, conforme o lugar de nascimento do autor, perceberemos que os escritos por autóctones são minoria. O motivo

\footnotetext{
* Mestranda UNICAMP.
} 
superficial, o exótico, o pitoresco só atrai os de fora. Para o autóctone obter a imagem de sua cidade, são necessárias motivações diferentes [...]. (BENJAMIN, apud Bolle, 2000, p.316)

Vários exemplos deste olhar podem ser encontrados no livro Os viajantes olham Porto Alegre, organizado por Valter Antônio Noal Filho e Sérgio da Costa Franco. Neste livro constam trechos de relatos de viajantes que estiveram em Porto Alegre entre os anos de 1754 e 1941. Porém, neste trabalho me concentrarei nos relatos do século XIX.

Neste período, já havia se esboçado em nosso país cidades relativamente grandes, e os viajantes oriundos da moderna Europa observaram e registraram suas impressões de nossas capitais, que estavam dando seus primeiros ares de metrópole. Segundo Benjamin, no século XIX, a imagem da metrópole fazia parte do que ele chamou de sonhos coletivos, que se materializaram nas construções que formaram as grandes cidades e que estariam fundando o que viria a ser a identidade do século XX.

Sendo assim, esta época é muito interessante para se observar o "fenômeno urbano". Willi Bolle, em Fisiognomia da metrópole moderna, baseado nas idéias de Benjamin, afirma que é entre os séculos XIX e XX que há

[...] o choque entre, de um lado, os ideais da "modernização" e do "progresso" e, de outro, o atraso e a barbárie reais: com relação à população mundial aumentaram a pobreza e a miséria, graves problemas econômicos continuam sem solução, os valores do humanismo caíram em descrédito, e em toda a parte observa-se uma decadência da ética política e um aumento da violência e da destruição. O conceito de metrópole ("cidade mãe"), uma categoria histórica que ressurgiu na era do imperialismo oitocentista com as cidades de Londres e Paris (a "capital do século XIX”), revela-se, juntamente com sua contraparte, a "periferia", um instrumento útil de reflexão sobre as relações entre países altamente desenvolvidos (hegemônicos) e atrasados (dependentes). (BOLLE, 2000, p.18)

No século XIX, as grandes cidades estavam apenas surgindo (ou ressurgindo) e no Brasil ainda não havia metrópoles propriamente ditas. Contudo, Porto Alegre queria ser grande, e muitas vezes seus habitantes a julgavam em pé de igualdade com os processos de modernização correntes no resto do mundo dados alguns traços de desenvolvimento que a cidade apresentava. Em O Imaginário da Cidade, Sandra Pesavento comenta este aspecto da Porto Alegre do século XIX:

Tal como no Rio de Janeiro - mas levando em conta a diferença de escala entre as duas cidades - Porto Alegre iria também potencializar a capacidade metonímica de hipervalorização das marcas da renovação urbana.

[...] Ações de intervenção eram empreendidas, mas o que importa registrar é a sensação de ser metrópole, propiciada pela transformação de uma parte, tomada pelo conjunto. (PESAVENTO, 2002, p.320)

Vários viajantes discorreram sobre estas intervenções em prol da modernização da nossa capital. O alemão Johann Karl Dreher, que chegou em Porto Alegre em 1840, aponta o 
surgimento de casas de negócios, firmas e estabelecimentos de importação, mostrando assim o crescimento da indústria e do comércio, sinais de chegada da preconizada Modernidade:

O comércio de importação era então representado por duas casas, a de João Diederichs e de Hermann Cordes. Além disso, a casa Hugentobler tinha somente uma filial de manufaturas inglesas e as americanas eram representadas por um certo senhor Falkmann. Naquele tempo já existiam duas casas de artigos coloniais (secos e molhados) como firmas importantes, Friedrich Bier e Bormann \& Cia., representada por Bormann e Scheller. (DREHER apud NOAL FILHO e FRANCO, Vol. 1, 2004, p.80)

O francês Arsène Isabelle, que esteve em Porto Alegre por volta de 1833, discorre sobre o traçado e o sistema de calçamento das ruas. Como nesta época o núcleo da cidade se encontrava onde hoje é o bairro Centro, havia constantes esforços para o nivelamento das ruas, dada a topografia um pouco irregular desta parte da cidade. Existia toda uma preocupação da prefeitura em nivelar, alinhar e calçar os logradouros:

A cidade é tão regular quanto pode permitir a desigualdade de uma colina um pouco íngreme, sobretudo na parte superior. Procura-se, aliás, diariamente, nivelar o terreno e alinhar as ruas, que são todas dotadas de calçadas e dirigidas para os quatro pontos cardeais. As que vão para o norte e para o sul são as menos agradáveis de freqüentar por serem traçadas no sentido da altura. As que são paralelas à direção da colina são mais bonitas: duas, entre outras, a rua da Praia e a da Igreja, são notáveis pelo grande número de lindas casas que apresentam. (ISABELLE apud NOAL FILHO e FRANCO, Vol. 1, 2004, p.70)

Outro fator importante que demonstrava o quanto Porto Alegre crescia era o aumento muito rápido do número de habitantes. Um dos principais fatores para este crescimento foi a colonização alemã, que, iniciada em 1824, trouxe muitos habitantes para a cidade, contribuindo de maneira decisiva para o seu desenvolvimento e, conseqüentemente, modernização. O alemão Johann Eduard Wappäus, que visitou nossa capital em torno de 1834, comenta (posteriormente) este aspecto:

A população de Porto Alegre, no ano de 1863, já era de 17.765 habitantes e atualmente beira entre 20 a 24.000 almas. Encontram-se entre elas cerca de 3.000 alemães, sendo a maioria descendente dos antigos colonos de São Leopoldo, aos quais se uniram muitos soldados e oficiais, desligados da Legião Alemã, constituindo um elemento importante da população. (WAPPAÜS apud NOAL FILHO e FRANCO, Vol. 1, 2004, p.151)

Também a presença de prédios importantes, como os administrativos, por exemplo, e o surgimento de casas suntuosas e elegantes já denotavam uma cidade que queria dar os seus primeiros ares de grande centro. Wappäus menciona alguns destes prédios importantes, como a Tesouraria Provincial e a Alfândega, bem como a presença de casas já com três andares no então principal logradouro da cidade, a Rua da Praia. Segundo ele, Porto Alegre

[...] é uma das capitais provinciais mais bem construídas e a mais simpática do Império. A sua rua principal, a Rua da Praia, estende-se ao longo da margem noroeste da península, na qual se encontra o porto. É uma rua larga, ocupada por casas, em parte, de até três andares, conservadas e até suntuosas, e vai dar na Praça da Harmonia, grande e simétrica; e pelo lado oposto, vai dar na Praça do Paraíso, provida de um Mercado e onde também estão localizados os prédios oficiais da Alfândega, da Tesouraria Provincial, do Arsenal de Guerra e da Marinha. (WAPPAÜS apud NOAL FILHO e FRANCO, Vol. 1, 2004, p.150) 
Além de pavimentação e belas casas, as ruas porto-alegrenses do século XIX também se defrontaram com mais um aspecto do progresso: a velocidade dos meios de transporte cada vez mais eficientes. Neste período, começavam a ser implantados os bondes, que levavam as pessoas do centro da cidade aos subúrbios, dado que era comum aos porto-alegrenses se dirigirem a estes bairros (Santa Tereza, Menino Deus e Partenon, principalmente) para passearem por suas paisagens ainda repletas de natureza e não urbanizadas.

O viajante alemão Wilhelm Breitenbach, que visitou nossa cidade por volta de 1880 , discorre sobre este meio de transporte, descrevendo os itinerários referidos acima e explicando seu funcionamento. Estes bondes eram de tração animal, e suas três estações finais se encontravam fora da cidade:

Uma grande comodidade, mesmo em cidades brasileiras menores, foram e são os bondes tracionados por cavalos e mesmo por burros, aliás, por asnos e mulas e não, propriamente, por cavalos. No Brasil, o transporte ferroviário tracionado por cavalos, é geralmente denominado bonde. Eu não consegui descobrir como se chegou a essa denominação. Mais recentemente, somaram-se aos bondes, as carruagens, também puxadas por cavalos. (BRETEINBACH apud NOAL FILHO e FRANCO, Vol. 1, 2004, p.184)

Percebe-se, através da análise de relatos de viajantes do século XIX, a chegada lenta, mas constante, da Modernidade na capital do Rio Grande do Sul. Apesar de ainda pequena, Porto Alegre já marchava na direção do progresso, ao incrementar seus meios de transporte, prédios, casas e ruas.

\section{Referências}

BARREIRO, José Carlos. Imaginário e viajantes no Brasil do século XIX: cultura e cotidiano, tradição e resistência. São Paulo: Editora UNESP, 2002.

BENJAMIN, Walter. Walter Benjamin. São Paulo: Ática, 1985. p. 30-43: Paris, capital do século XIX.

BENJAMIN, Walter. Walter Benjamin. São Paulo: Ática, 1985. p. 44-122: A Paris do Segundo Império em Baudelaire.

BOLLE, Willi. Fisiognomia da metrópole moderna. São Paulo: EDUSP, 2000.

GOMES, Renato Cordeiro. Todas as cidades , a cidade: literatura e experiência urbana. Rio de Janeiro: Rocco, 1994.

NOAL FILHO, Valter Antonio, FRANCO, Sergio Costa. Os viajantes olham Porto Alegre. Porto Alegre: Anaterra, 2004. 2 vls. 
PESAVENTO, Sandra Jatahy. O imaginário de cidade: visões literárias do urbano - Paris, Rio de Janeiro, Porto Alegre. Porto Alegre: Editora da Universidade/UFRGS, 1999.

SANTOS, Paulo Ferreira Formação das cidades no Brasil Colonial. Rio de Janeiro: Editora UFRJ, 2001. 